\begin{tabular}{lll} 
Review Article & $\begin{array}{l}\text { Yönetim, Ekonomi, Edebiyat, } \\
\text { İslami ve Politik Bilimler } \\
\text { Dergisi,3(1): 29-43, }\end{array}$ & $\begin{array}{l}\text { JOMELIPS - Journal of } \\
\text { Management Economics Literature } \\
\text { Araştırma Makalesi }\end{array}$ \\
$\begin{array}{l}\text { Islamic and Political Sciences } \\
\text { DOI: 10.24013/jomelips.392324 }\end{array}$ & 30 Haziran/June, 2018 & e-ISSN :2547-9512 \\
\hline
\end{tabular}

\title{
Kişilerin Alman Marka Otomobil Tercihlerinde Bazı Tutum ve Davranışların Rolü: Bölgesel Bir Uygulama
}

\author{
Dr. Öğr. Üyesi Hakan TUNÇ ${ }^{1^{*}}$ \\ ${ }^{1}$ Mehmet Akif Üniversitesi, İktisadi ve İdari Bilimler Fakültesi, Bankacılık ve Finans Bölümü, \\ htunc@mehmetakif.edu.tr
}

$\ddot{\mathbf{O} z}$

Türkiye'de son yıllarda ekonomik gelişme ile birlikte araç talebinde hızlı artışlar gözükmektedir. Kişilerin kullanılabilir gelirindeki artışın yanında kredi sisteminin de piyasayı desteklemesi otomotiv satışlarını artırmıştır. Yerli araba üretimine ilişkin yoğun gündemler yaşanırken kişilerin özellikle Alman marka otomobillere olan ilgisi tematik tartışmalara neden olmaktadır. 2016 yılında Türkiye' de 983 bin araç satış1 gerçekleşmiştir. Aynı yıl alman marka araçlarda 330 bin adet satış gerçekleşirken, satılan 3 araçtan biri alman markasına sahiptir. Ayrıca 2016 yılında dünyada 99 milyon adet araç satışı gerçekleşirken, dünyada satılan 100 araçtan birinin Türkiye'de satıldığı tahmin edilmektedir.

Bu çalışmanın amacı son yıllarda Türkiye'de hızla talebi artan alman marka otomotivlere olan ilgiye, bazı tutum ve davranışların etkisini araştırmaktır. Uygulama kısmında İstanbul'da rastgele örneklem yöntemiyle 258 kişiye anket uygulaması yapılmış olup, veriler logit modeli yardımıyla incelenmiştir. Sonuç itibariyle kişilerin tüketim yaparken imaj algısı, güvenlik algısı, tek bir kere satın alıp uzun dönem kullanma algısı arttıkça Alman marka otomobillere olan ilgi artmaktadır.

Anahtar Sözcükler: Logit, Almanya, Otomobil

Jel Kodu: R21, R1,F10

*Sorumlu Yazar (Corresponding Author):

Mehmet Akif Üniversitesi, İktisadi ve İdari Bilimler Fakültesi, Bankacılık ve Finans Bölümü, htunc@mehmetakif.edu.tr
Geliș (Received) : 08.02.2018

Kabul (Accepted) : 26.06.2018

Basım (Published) : 30.06 .2018 


\title{
Persons That German Brand Automobile Preference The Role Of Some Attitudes and Behaviors: A Regional Practice
}

\begin{abstract}
Turkey in recent years along with economic development there is a rapid increase in demand for cars. Besides the increase in available revenue for people and supporting the credit system in the market automotive sales increased. While there are intense agendas for domestic car production. While there are intense agendas for domestic car production the interest of people especially to German cars, it may cause thematic discuss. In 2016, 983 thousand cars were sold in Turkey. The same year, German car brand 330 thousand cars sold in Turkey . In 2016, one of the three cars sold in Turkey has the German brand. Also in 2016 the world is estimated at 99 million cars and It is estimated that one in Turkey sold 100 vehicles sold in the world.
\end{abstract}

The aim of this study is rapidly increasing in recent years, demand for German brand in Turkey to investigate the role of some of the attitudes and behaviors of interest to the automotive industry. In the application part, 258 people were questionnaire in İstanbul by random sampling method, Analyzes were made with logit model. As a result, the interest in German-brand cars is increasing as consumers increase their perception of image, security, single-take and long-term use.

Keywords: Logit, Germany, Car

Jel Kod: R21, R1,F10

\section{Giriș}

Bir ekonomide talebi etkileyen önemli faktörlerden biride zevk ve tercihlerdir. Talep teorisi, kişilerin bir malı satın alırken öncelikle o malı fiyatına duyarlı olduğunu varsayarken, fiyat duyarlılığı dışında da bazı faktörlerin talebi etkilediğini savunmuştur. Kişilerin zevk ve tercihlerinin talep süreçlerinde etkili olması talebe konu olan malın cinsi ile de alakalıdır. İktisat teorisinde çok fazla mal ayrımı olmakla birlikte çalışmanın konusuyla alakalı olarak mallar üçe ayırılabilir. Birincisi lüks mallar kişinin gelirinden 
yüksek pay alan, düşük mallar kişinin gelirinden düşük pay alan ve zorunlu mallar ise yaşamın sürdürülebilmesi için tüketilmesi zorunlu olan mallardır(Ünsal,1998, s.73). Bu ayrım içerisinde çalışmanın konusu olan otomobillerin lüks mal statüsünde incelenebileceği ve bu malların talep esnekliklerinin yüksek olduğu söylenebilir.

İktisat teorisi, rasyonel olan bireylerin bir mal tercih ederken fayda odaklı olacaklarını ve kendileri için daha çok faydalı olanı, daha az faydalı olana tercih edeceklerini savunmaktadır. Fayda odaklılık, içerik olarak geniş bir kapsama sahip iken kişilerin otomobil tercihlerinde marka, fiyat, güvenlik, teknik özellikler, yakıt tasarrufu, çevre duyarlılık gibi konularda sağlanacak potansiyel faydanın o malın talebinde önemli bir tercih nedeni olduğu ifade edilmektedir(Ersoy ve Firat, 2006, s.204).

Kişilerin otomobil tercihini etkileyen faktörler daha önce birçok araştırmacı tarafından incelenmiş olmakla birlikte kişiler kendilerine uygun otomobili tercih ederken öncelikle segment tercihi yapmakta (Terzi, Hacaloğlu ve Aladağ, 2006, s.45) daha sonra ikinci el değerlemesinden satış sonrası hizmetlere, vergi oranlarından aracın yol tutuşuna kadar bir çok kısıt altında tercihini yapmaktadır. Bu kriterler kişilere göre değişmekle birlikte, kişilere ait demografik ve kültürel faktörlerini bu tercihlerde etkili olduğu ifade edilmektedir(Toksarı, İnal, 2011, s.83). Örneğin akademisyenler üzerinde yapılan bir çalışmada aylık gelirin çok etkili, cinsiyetin ve yaşın otomobil tercihinde etkili olduğu saptanmıştır(Ruhlusaraç ve Nakip, 2016, s.100). Kişilerin aylık harcamalarının artmasının bir otomobile sahip olma olasılığını azalttığı ve kişilerin bir otomobile sahip olmasını etkileyen en önemli faktörün kişilerin yıllık toplam kullanılabilir gelir olduğunu ifade eden çalışmalar mevcuttur(Akay, ve Tümsel,2015,s.35).

Otomobil sektöründe İkinci el talebini etkileyen faktörler incelendiği çalışmalar da ise aracın kazalı olma durumu, yakıt tüketimi, fiyatı ve performansı en çok dikkate alınan konular arasında iken dış görünümü, kredi imkânı ve aracın renginin de en az dikkate alınan konular olduğu saptanmıştır(Akçi, 2016,s.329). Kişilerin otomobil satın alma niyetinde ağızdan ağıza iletişimin etkili olduğu( Karadirek, 2017, s.185). ve kişilerin kredi kartı sahip olmasının dahi bir otomobil sahip olmayı etkilediği değişik çalışmalarda vurgulanmıştır(Yayar, Çoban ve Tekin,2015, s.603). ). Ayrıca kişiler otomobil tercih ederken bilgi ve iletişim kanallarının da etkili olduğu (Rijnsoever, Castaldi ve Dijst, 2009). 
birinci ve ikinci elde sadece otomobil tanıtımı ve satışı yapan E-ticaret sitelerinin, pazarı etkilediği ifade edilmiştir. Günümüz koşullarında kullanılan otomobil adeta zenginliğin simgesi haline gelmiştir. Bu simge Türk toplumunda da bazen kendini göstermekte ve rasyonel tercih unsurlarının önüne geçebilmektedir(Güneş, 2012, s.229

$\mathrm{Bu}$ faktörler içerisinde marka faktörü otomobil sektöründe son yıllarda ön plana çıkmaktadır. Sektörde faaliyet gösteren çok fazla fïrma olması ve bu firmaların birbirine yakın mallar üretmesi, kişilerin marka hassasiyetini artırırken, son yıllarda Alman otomobil markalarına olan ilgi ve alakanın artmasının önemli bir nedeni de bu firmaların rakiplerine göre marka değerlerinin yüksek olması ve tüketici zevk ve tercihlerini iyi analiz edip bu doğrultuda mallar üretebilmeleridir.

\section{1- Dünyada ve Türkiye'de Otomotiv Sektörü}

Otomotiv sektörü Türkiye'de ve dünyada hızlı gelişen bir sektör olarak kendini göstermektedir. Dünyada 2016 yılında 99 milyon adet 2017 yılında ise yaklaşık 100 milyon adet araba satıldığ tahmin edilmektedir(ODD ${ }^{1}, 2017$, s.1). Ayrıca 28 üyeli Avrupa Birliği ülkeleri ile EFTA ülkelerinde birlikte 15 milyonun üzerinde araba satışı gerçekleşmiştir(ODD, 2018, s.3). Türkiye otomotiv piyasası incelendiğinde ise otomobil ve hafif ticari araç toplam piyasası 2017 yılında bir önceki yıla göre \%2,8 azalarak 956.194 adet olarak gerçekleşmiştir. 2016 y1lında ise 983,720 adet toplam satış adedi ile piyasa sonuçlanmıştır(ODD,2018, s.17). İstatistikler göstermektedir ki dünyada satılan 100 arabadan biri Türkiye'de satılmaktadır.

Segment cinsinden bakıldığında 2017 sonu itibariyle en yüksek araba satışı C segmenti araçlarda 378.000 adet ile gerçekleşmiştir. Aynı dönemde kasa tipleri incelendiğinde sedan otomobiller \%49 pay sahibi iken SUV araçlar 129.354 satış ile \% 18 pay sahibidir. 2017 yılı aralık ayı itibariyle satılan birinci el otomobillerin \% 60'1 otomatik şanzıman \% 40'1 düz şanzıman olarak gerçekleşmiştir. İkinci el piyasasında 2016 yılında 4.8 milyon araba el değiştirmiş olup aynı yılda 4507 adet hibrit araç satışı gerçekleşmiştir(ODD,2018). Türkiye'de satılan 100 otomobilden 15 'i birini el iken 85 'i ikinci eldir.

\footnotetext{
1 "Otomotiv Distribütörleri Derneği
} 
Türkiye otomobil ihracatında da önemli gelişmeler yaşanmaktadır. Son yıllarda üretimin artmasının en önemli nedeni ihracattaki artışlardır. Tuik verilerine göre Binek otomobil ve sanayi ile ilgili taşımacılık araç ve gereçleri ihracat toplamı 2016 yılında 16 milyar doların üstündedir. 2016 yılında toplam ihracatın 142 milyar dolar olduğunu bir süreçte otomobil sektörünün toplam ihracattaki payı \% 11 civarındadır. Şekil 1 de Türkiye'nin 2011 -2016 yılları arasında otomobil ve sanayi ile ilgili taşımacılık araç ve gereçleri ihracatı toplamının yıllara göre grafiği verilmiştir. Grafikte artan eğilimi dikkat çekerken, Türkiye 2015 yılında otomotiv ürünleri ihracatında dünyada 19. sırada yer almıştır. 2015 yılında dünyada 1.3 trilyon dolar otomotiv ihracatı gerçekleşirken en çok ihracat 235 milyar dolar ile çalışmanın kapsamında yer alan Almanya tarafından gerçekleștirilmiştir(TUIK, 2016, s.1).

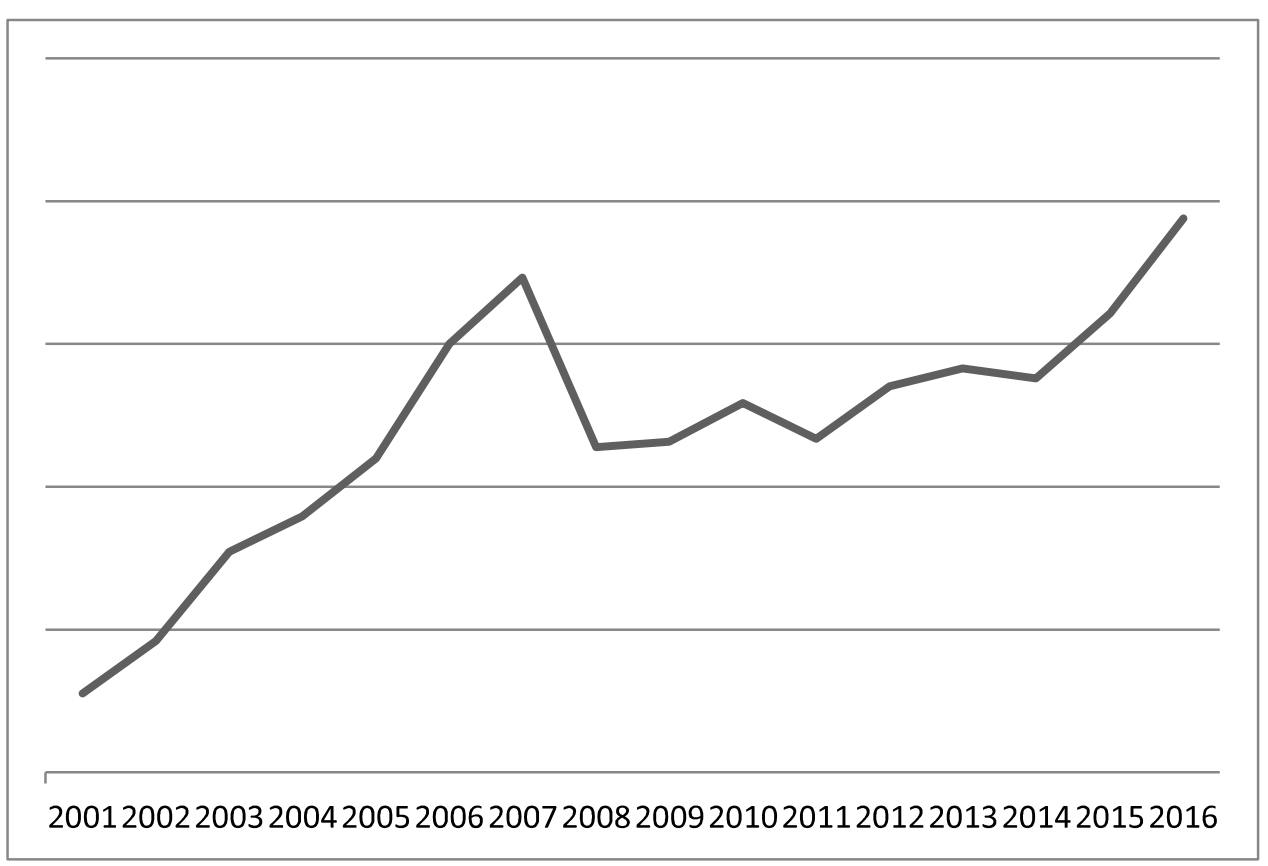

Şekil 1: Türkiye'de 2001-2016 Yılları Arası Otomobil İhracatı

\section{Kaynak: Tuik Verileri kullanılarak yazar tarafından hazırlanmıştır.}

\section{2- Türkiye'de Alman Otomototiv Sektörü}

Türkiye'de son y1llarda Alman marka otomobillere yoğun ilgi olduğu bilinmektedir. Özellikle lüks araç üretiminde ön plana çıkan Alman otomotiv firmaları Türk vergi sisteminede uygun araçlar üreterek, pazardaki rekabet üstünlüğünü artırmıştır. Ayrıca Alman marka otomotiv firmaları tüketici zevk ve tercihleri doğrultusunda inovasyon 
yapma eğilimleride yüksektir. 2015 yılı verilerine göre dünyada en çok Ar-Ge yapan 20 firma içerisinde Volkswagen grup 15 milyar dolar Ar-Ge harcaması ile birinci sırada yer almıştır. Başka bir Alman otomotiv firması olan Daimler firmasıda 7.3 milyar dolar Ar-Ge harcaması ile dünyada en çok Ar-Ge yapan fïrma 20 fïrma arasına girmiştir(Pişkin, 2017, s.14).

Tablo:1 Almanya Menşeyli Binek Araba İthalatı (1997-2017)

\begin{tabular}{|c|l|l|l|l|l|}
\hline Yllar & Ülke & Tarife Türü & $\begin{array}{l}\text { Almanya } \\
\text { Itthalatı }\end{array}$ & $\begin{array}{l}\text { T.Bin. Araba } \\
\text { Ithalatı }\end{array}$ & $\begin{array}{l}\text { T.Bin.A. } \\
\text { Ith/Alm.Ith. }\end{array}$ \\
\hline $\mathbf{1 9 9 7}$ & Almanya & B.Otomobilleri & 631.321 .890 & 1.673 .754 .930 & 0,377189 \\
\hline $\mathbf{1 9 9 8}$ & Almanya & B.Otomobilleri & 534.643 .204 & 1.392 .405 .649 & 0,383971 \\
\hline $\mathbf{1 9 9 9}$ & Almanya & B.Otomobilleri & 423.312 .704 & 1.324 .690 .982 & 0,319556 \\
\hline $\mathbf{2 0 0 0}$ & Almanya & B.Otomobilleri & 738.013 .370 & 2.595 .868 .200 & 0,284303 \\
\hline $\mathbf{2 0 0 1}$ & Almanya & B.Otomobilleri & 199.438 .970 & 586.806 .639 & 0,339872 \\
\hline $\mathbf{2 0 0 2}$ & Almanya & B.Otomobilleri & 342.609 .116 & 813.265 .650 & 0,421276 \\
\hline $\mathbf{2 0 0 3}$ & Almanya & B.Otomobilleri & 862.916 .226 & 2.219 .740 .602 & 0,388746 \\
\hline $\mathbf{2 0 0 4}$ & Almanya & B.Otomobilleri & 1.321 .099 .796 & 4.213 .556 .246 & 0,313536 \\
\hline $\mathbf{2 0 0 5}$ & Almanya & B.Otomobilleri & 1.076 .663 .023 & 4.296 .117 .348 & 0,250613 \\
\hline $\mathbf{2 0 0 6}$ & Almanya & B.Otomobilleri & 1.106 .796 .877 & 4.268 .704 .396 & 0,259282 \\
\hline $\mathbf{2 0 0 7}$ & Almanya & B.Otomobilleri & 1.263 .896 .048 & 4.746 .753 .501 & 0,266265 \\
\hline $\mathbf{2 0 0 8}$ & Almanya & B.Otomobilleri & 1.175 .806 .856 & 4.551 .805 .485 & 0,258317 \\
\hline $\mathbf{2 0 0 9}$ & Almanya & B.Otomobilleri & 1.433 .280 .541 & 4.265 .400 .937 & 0,336025 \\
\hline $\mathbf{2 0 1 0}$ & Almanya & B.Otomobilleri & 2.385 .555 .153 & 6.819 .601 .178 & 0,349809 \\
\hline $\mathbf{2 0 1 1}$ & Almanya & B.Otomobilleri & 2.983 .401 .220 & 8.474 .786 .820 & 0,352033 \\
\hline $\mathbf{2 0 1 2}$ & Almanya & B.Otomobilleri & 2.791 .653 .374 & 7.248 .446 .647 & 0,385138 \\
\hline $\mathbf{2 0 1 3}$ & Almanya & B.Otomobilleri & 3.433 .707 .089 & 9.126 .820 .426 & 0,376222 \\
\hline $\mathbf{2 0 1 4}$ & Almanya & B.Otomobilleri & 3.105 .483 .495 & 7.717 .928 .205 & 0,402373 \\
\hline $\mathbf{2 0 1 5}$ & Almanya & B.Otomobilleri & 3.609 .207 .802 & 9.223 .243 .498 & 0,391317 \\
\hline $\mathbf{2 0 1 6}$ & Almanya & B.Otomobilleri & 3.423 .276 .204 & 9.839 .843 .675 & 0,347899 \\
\hline $\mathbf{2 0 1 7}$ & Almanya & B.Otomobilleri & 2.576 .790 .074 & 7.503 .198 .600 & 0,343426 \\
\hline
\end{tabular}

Kaynak: Tuik Verileri kullanılarak yazar tarafından hazırlanmıştır. 
Tablo:1'de son 20 yılda Türkiye'nin Almanya'dan yaptı̆ğ binek otomobil ithalatı, son 20 yılda yapılan toplam binek araba ithalatı ve Almanya'dan yapılan binek otomobil ithalatının toplam binek araba ithalatına oranı verilmiştir. İlgili 20 yıllık süreçte Alman marka otomobil ithalatının 5.7 kata kadar arttığı ve Almanya'dan yapılan binek araba ithalatının toplam binek araba ithalatına oranının yüzde kırklara kadar çıktığı görülmüştür. Son yirmi yıl içerisinde en çok Almanyadan binek araba ithalatı yapılan yıl 3.6 milyar dolar ile 2015 yılı olmuştur.

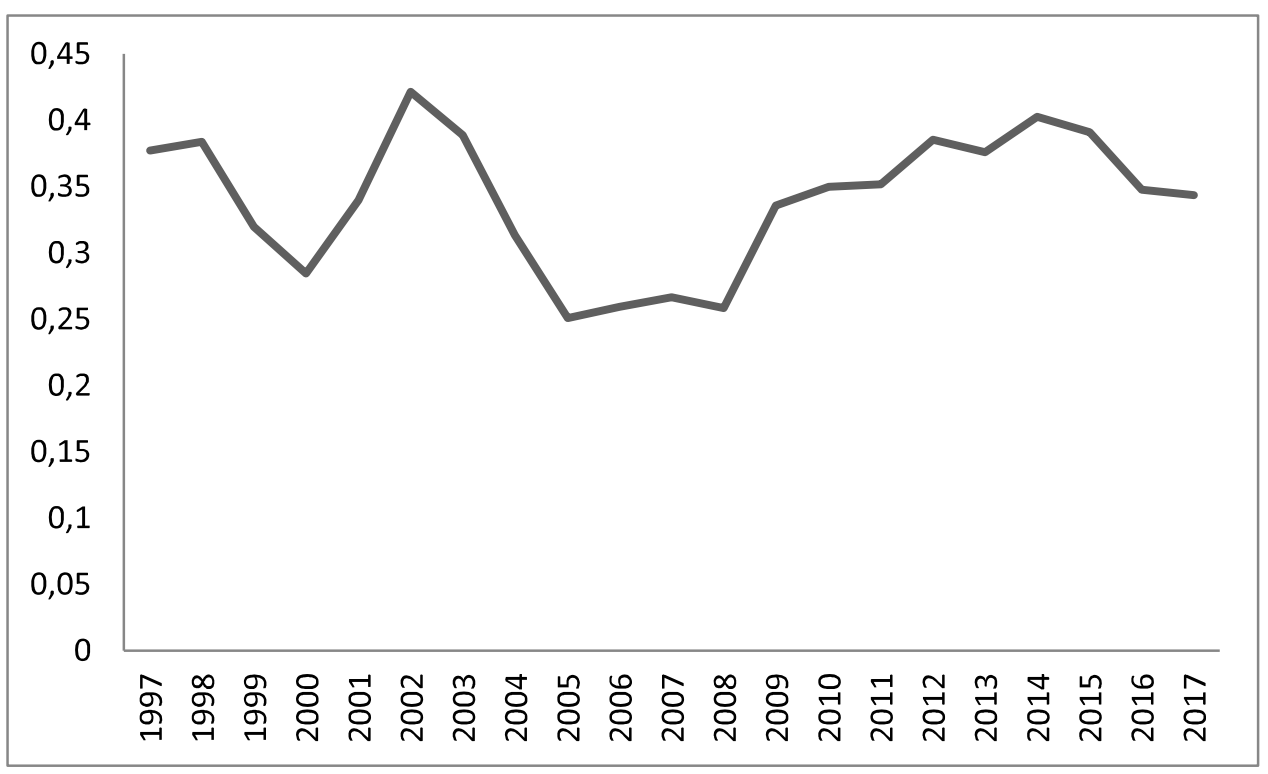

Şekil 2 Toplam Binek Araba İthalatı/ Almanya İthalatı Eğilimi (1997-2017)

\section{Kaynak: Tuik Verileri kullanılarak yazar tarafından hazırlanmıştır.}

Şekil 2 de son 20 yılda Alman binek otomonil ithalatının toplam binek araba ithalatına oranının grafiği verilmiştir. 2010 yılında başlayan ve 2017 yılına kadar süren büyüme eğilimi dikkat çekmektedir. Ayrıca 2001 Türkiye'de yaşanan ekonomik krizin ve 2008 yılında yaşanan Amerika kaynaklı finansal krizin ilgili dönemlerinde grafik aşşağı yönlü çektiği gözükmektedir.

Tablo:2 Almanya Otomotiv Firmaları Satışları(2010-2017,Adet)

\begin{tabular}{|c|c|c|c|c|c|c|c|c|c|}
\hline & $\mathbf{2 0 1 0}$ & $\mathbf{2 0 1 1}$ & $\mathbf{2 0 1 2}$ & $\mathbf{2 0 1 3}$ & $\mathbf{2 0 1 4}$ & $\mathbf{2 0 1 5}$ & $\mathbf{2 0 1 6}$ & $\mathbf{2 0 1 7}$ & Toplam \\
\hline AUDI் & 9.656 & 12.064 & 13.720 & 14.987 & 17.809 & 20.279 & 22.005 & 21.585 & 132.105 \\
\hline
\end{tabular}




\begin{tabular}{|c|c|c|c|c|c|c|c|c|c|} 
BMW & 12.034 & 15.018 & 15.247 & 20.705 & 26.174 & 31.221 & 27.166 & 19.564 & 167.129 \\
\hline MERCEDES & 17.562 & 21.025 & 21.964 & 30.444 & 31.128 & 38.790 & 40.736 & 34.631 & 236.280 \\
\hline OPEL & 41.572 & 54.437 & 49.825 & 55.993 & 39.255 & 47.000 & 55.471 & 44.707 & 388.260 \\
\hline PORSCHE & 390 & 442 & 497 & 517 & 588 & 861 & 827 & 670 & 4.792 \\
\hline SEAT & 5.113 & 6.059 & 5.811 & 11.065 & 12.697 & 16.911 & 20.637 & 16.064 & 94.357 \\
\hline SKODA & 6.332 & 7.590 & 10.118 & 12.833 & 14537 & 22.107 & 28.876 & 24.679 & 127.072 \\
\hline VOLKSWAGE & 63.840 & 81.911 & 92.840 & 112.05 & 108.64 & 139.04 & 134.53 & 117.48 & 850.353 \\
N & & & & 6 & 7 & 3 & 5 & 1 & \\
\hline & 156.49 & 198.54 & 210.02 & 258.60 & 250.83 & 316.21 & 330.25 & 279.38 & 2.000 .34 \\
Toplam & 9 & 6 & 2 & 0 & 5 & 2 & 3 & 1 & 8 \\
\hline
\end{tabular}

Kaynak: ODD verileri kullanılarak yazar tarafından hazırlanmıștır.

Tablo 2 'de Türkiye de satış yapan Alman otomotiv firmalarının satış rakamları verilmiştir. Rakamlar incelendiğinde son 8 yılda iki milyonun üzerinde alman marka otomotiv satışı gerçekleşmiştir. 2016 yılında 330.253 adet alman marka otomotiv satılırken 2016 yılında Türkiyede ortalama satılan üç arabadan biri Alman marka otomobili olmuştur. Ayrıca 2010 ile 2016 yılları arası rakamlar incelendiğinde audi 2.23 kat, bmw firmas1 1.6 kat, mercedes benz firması 2.31 kat, opel firması 0.07 kat, porsche firması 2.12 kat, seat firması 4 kat, skoda firması 4.5 kat ve volkswagen firması 2.1 kat satışlarını artırmıştır. Skoda ve Seat firmalarının satışalrındaki artış oranı dikkat çekicidir.

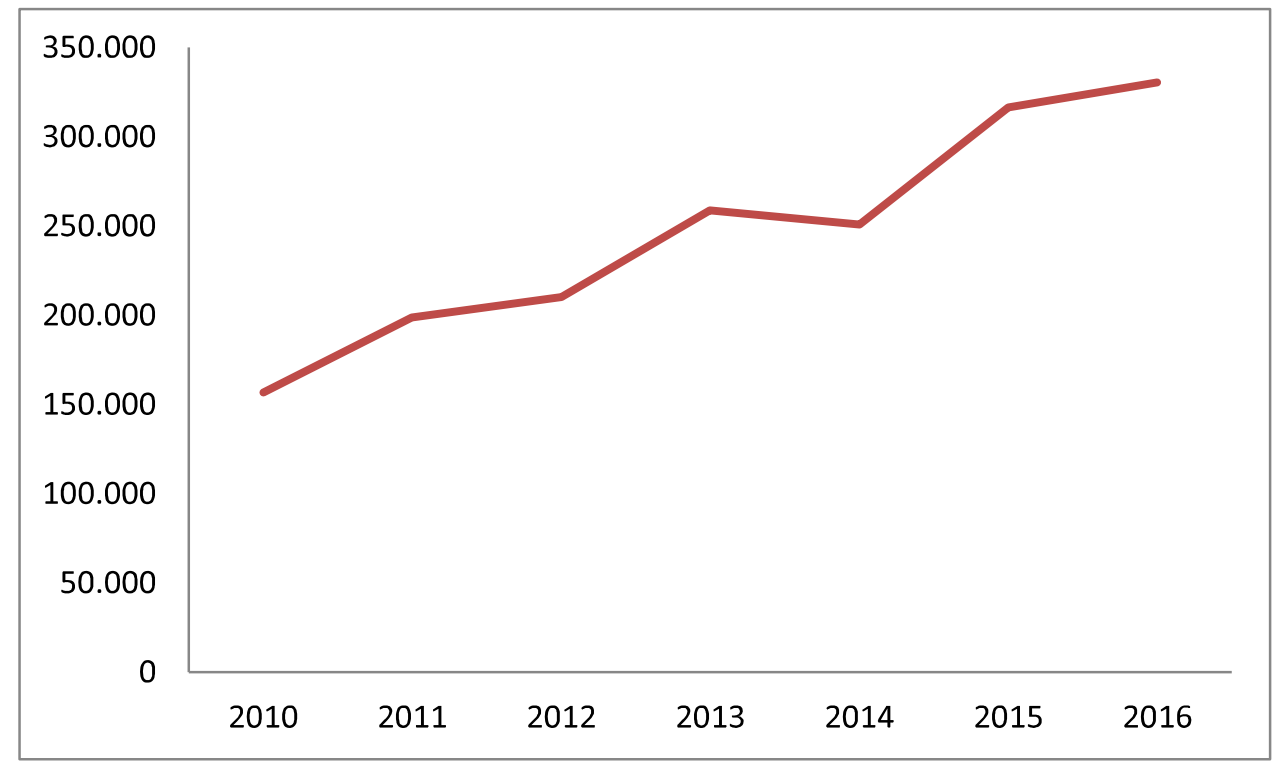


Şekil 3: Alman Otomotivleri Talebi (2010-2016)

\section{Kaynak: ODD verileri kullanılarak yazar tarafından hazırlanmıştır.}

Şekil 3 de 2010 ve 2016 yılları arasındaki toplam Alman marka otomobil talebinin grafiği verilmiştir. Grafiğin büyüme eğilimi çok net bir biçimde gözükmektedir. Ayrıca şekil 4'de Türkiye'de marka değeri yüksek olan 3 büyük markanın aynı dönemdeki satış rakamlarının grafiği verilmiştir. Grafik çok net göstermektedir ki 3 markaya da son yıllarda artan talep eğilimi söz konusudur. Ayrıca üç marka 2010-2017 yılları arasında yaklaşık 535 bin adet satış gerçekleştirmiştir. Bu durum ayrıca ülkedeki kalkınma ve refah artışını da göstermektedir.

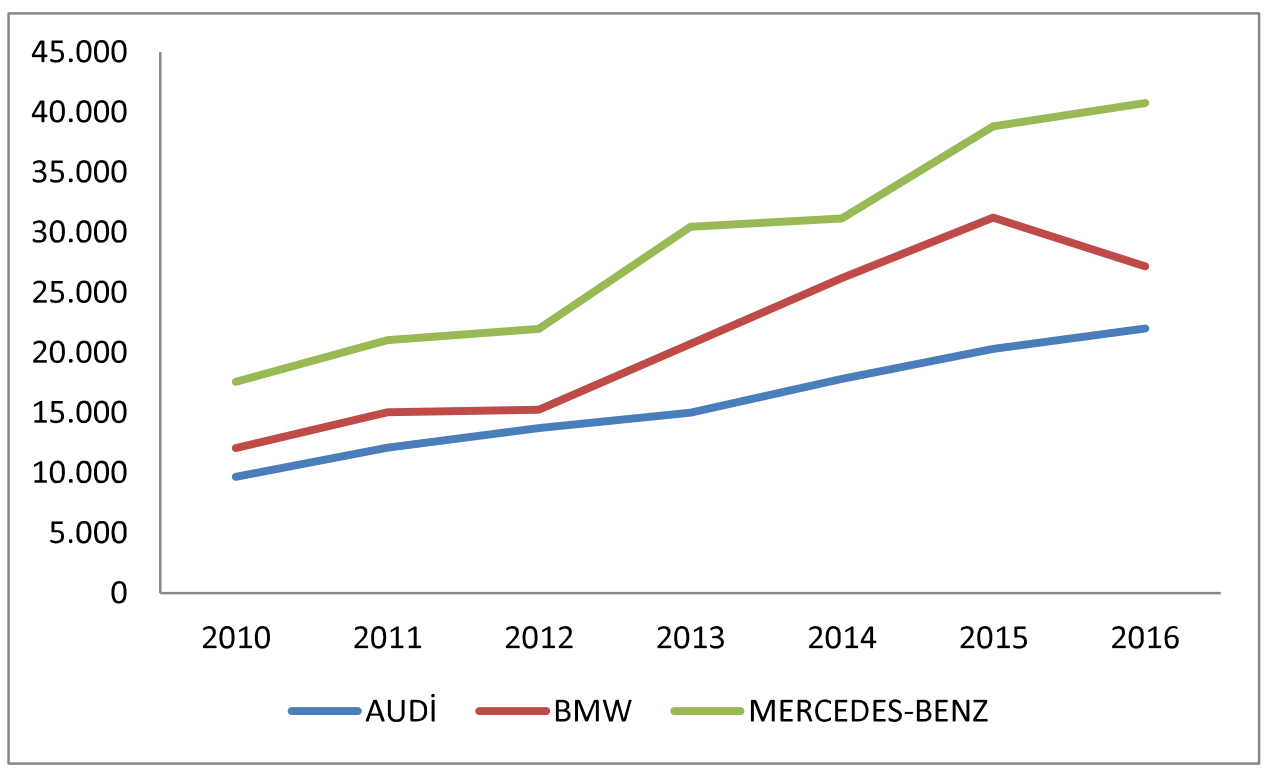

Şekil :4 Audi, Bmw, Mercedes -Bens Talebi

\section{Kaynak: ODD verileri kullanılarak yazar tarafından hazırlanmıştır.}

\section{3- Araştırma da Kullanılan Veri Seti ve Yöntem}

Çalışmanın uygulama kısmında kişilerin Alman marka otomotiv tercihlerinde etkili olan bazı tutum ve davranışlar incelenmek amacıyla İstanbul da yaşayan 285 kişiye rastgele örneklem yöntemiyle anket uygulaması yapılmıştır. Anketin İstanbul da uygulanmasının 
temel nedeni Alman marka otomobillerin en çok bu bölgede satılması ve bu bölgenin kişi başına düşen milli gelir açısından Türkiye'nin en zengin bölgesi olmasıdır.

Çalışmada lojistik regresyon (logit) modeli kullanılmıştır. Logit modeli bağımlı değişkenin ikili yapıya sahip olduğu, bağımsız değişkenlerin ise sürekli veya kategorik değişkenlerden oluşabildiği bir tahmin modelidir. Logit modeli katsayı tahmininde en küçük kareler yöntemi yerine en çok olabilirlik yöntemini kullanmaktadır. Bu sebepten dolayı avantajlı bir biçimde model artıklarının normal dağılması ya da değişmeyen varyans varsayımlarına sahip değildir. Fakat bu modelde mutlaka bağımsız değişkenler arasında bir ilişkinin varlığı test edilmelidir( Şenel ve Alatlı, 2014 s.37).

Çalışmada kişilerin Alman marka otomotiv tercihlerini etkileyen bazı faktörlerin incelenmesi hedeflenmektedir. Bu bağlamda ankette kişilere maddi durumları elverse Alman marka otomobil tercihleri hususunda 5'li likert ölçekte soru sorulmuş olup, 1 cevabının kesinlikle katılmıyorum 5 cevabının kesinlikle katılıyorum olduğu kodlamada, ankete cevap veren 258 kişinin bu soruya verdiği cevapların ortalaması 3.18'dir. Bu durum bölgede kişilerin Alman marka otomobillere olan ilgisini ve alakasını göstermektedir. $\mathrm{Bu}$ değişken daha sonra bağımlı değişken olarak kullanmak amacıyla 1,2 cevapları yeniden 0 olarak 3,4,5 cevapları yeniden 1 olarak kodlanmış ve veri binary hale getirilmiştir. Anket güvenilirlik testinde Cronbach's Alpha değeri 0,83 çıkmış olup bu sonuç anketimizin güvenilir olduğunu göstermektedir. (Kalayc1,2005:405).

\section{3-1. Model Tahmin Sonuçları}

Kullanılan modelde bağımlı değişken olarak kişilerin Alman marka otomobillere olan tercihi kullanılırken bağımsız değişken olarak kişinin cinsiyeti, kişinin alman marka otomobillerdeki güvenlik algısı, kişinin birçok ürün almaktansa tekbir ürün tercih etme algısı, yabancı marka kullanmanın imaj olduğu algısı, ve yabancı marka kullandığında ithalatı artırdığına dair düşünce algısı seçilmiştir.

Tablo:3 Model Sonuçları

\begin{tabular}{|c|c|c|}
\hline & Omnibus-Ki-kare & Omnibus-Sig \\
\hline Step/Block/Model & 89,195 &, 000 \\
\hline
\end{tabular}




\begin{tabular}{|c|c|c|}
\hline & Ki-Kare & Sig \\
\hline Hosmer and Lemeshow Test & 6,956 &, 541 \\
\hline Cox \& Snell R Square & Nagelkerke R Square & \\
292 &, 405 & \\
\hline
\end{tabular}

Analizin ilk aşamasında kurulan logit modeli bütünsel olarak anlamlılığ 1 test edilmiştir. Bu kısmında modelimize bağımsız değişkenleri ilave ettiğimiz zaman modelin anlamlılı̆̆ını ölçülmektedir(Çokluk, 2010, s.1385). Tablo 2'deki Omnibüs olasılık(sig) değeri 0.05 den küçük çıktığı için modelimiz bir bütün olarak anlamlı çıkmıştır. Ayrıca Hosmer and Lemeshow Testi model veri uyumunu göstermektedir(Şenel ve Alatl1, 2014, s.40). Hosmer and Lemeshow Testinin olasılık değerinin $0.05^{\prime}$ den büyük çıktığ 1 için $(, 541)$ model veri uyumu

başarılıdır.

Tablo: 4 Sinıflandırma Tablosu

\begin{tabular}{|c|c|c|c|c|}
\hline \multicolumn{2}{|c|}{ Gözlemler } & \multicolumn{3}{c|}{ Tahminler } \\
\cline { 3 - 5 } & \multicolumn{2}{|c|}{$\begin{array}{c}\text { Alman Arabalarına } \\
\text { Olan İlgi }\end{array}$} & $\begin{array}{c}\text { Doğruluk } \\
\text { Yüzdesi }\end{array}$ \\
\cline { 3 - 4 } &, 00 & 1,00 & \\
\hline $\begin{array}{c}\text { Alman Arabalarına } \\
\text { Olan İlgi }\end{array}$ &, 00 & 52 & 35 & 59,8 \\
\cline { 2 - 5 } & 1,00 & 21 & 150 & 87,7 \\
\hline \multicolumn{4}{|l|}{} \\
\hline \multicolumn{2}{|l|}{ Başarı Oranı } \\
\hline
\end{tabular}

Tablo 4 de modelimize ilişkin sınıflandırma tablosu verilmiştir. Model, bağımsız değişkenler eklendiği zaman kişilerin ilgisizliğini gösteren sıfır cevabının(0) \%59 oranında, ilgisini gösteren bir(1) cevabını \% 87 oranında toplamda \% 78 oranında tahmin etmiştir.

Tablo:5 Logit Katsayı Sonuçları

\begin{tabular}{|c|c|c|c|c|c|}
\hline $\begin{array}{c}\text { Bağımlı Değişken: Alman } \\
\text { Arabalarına Olan İlgi }\end{array}$ & $\mathbf{B}$ & $\mathbf{E x p ( B )}$ & Wald & Sig & $\begin{array}{c}\text { 95\% C.I.for } \\
\text { EXP(B) }\end{array}$ \\
\hline Cinsiyet &,- 979 &, 376 & 8,171 &, 004 &, $192-, 735$ \\
\hline Güvenlik Algısı &, 983 & 2,674 & 40,913 &, 000 & $1,978-3,614$ \\
\hline
\end{tabular}




\begin{tabular}{|c|c|c|c|c|c|}
\hline $\begin{array}{c}\text { Tek bir tane markalı ürün alma } \\
\text { algısı }\end{array}$ &, 292 & 1,339 & 7,023 &, 008 & $1,079-1,661$ \\
\hline Marka kullanmanın imaj Algısı &, 403 & 1,496 & 9,833 &, 002 & $1,163-1,924$ \\
\hline İthalatı artırma düşüncesi &,- 394 &, 675 & 6,453 &, 011 &, $498-, 914$ \\
\hline
\end{tabular}

Tablo:5 de bağımsız değişkenlerimizin kişilerin Alma marka otomobilleri tercihini nasıl etkilediğini anlamaya yardımcı olan katsayıların tahmini Wald testi yardımıyla yapılmıştır. Tablo 5 incelendiğinde katsayılarımıza ilişkin olasılık değeri, 005'den küçük çıkmış olması katsayılarımızın istatistiksel olarak anlamlı olduğunu göstermektedir. Modelde ki B değerleri ilişkinin yönü hakkında bilgi verirken $\operatorname{Exp}(B)$ değeri bu ilişkinin gücü hakkında bilgi vermektedir.

Sonuçlar incelendiğinde kişinin cinsiyeti bayandan(1) baya(0) doğru kaydıkça Alman otomobillerine olan ilgi 0.37 kat artmaktadır. Kişinin Alman arabalarının güvenli olduğu algısı arttıkça, alman otomobillerine olan ilgisi 2.6 kat artmaktadır. Kişinin tek bir markalı ürün kullanma algısı arttıkça Alman arabalarına olan ilgisi 1.3 kat artmaktadır. Kişinin Marka kullanmanın bir imaj olduğuna dair algısı arttıkça Alman arabalarına olan ilgisi 1.5 kat artarken son olarak kişilerin aldıkları yabancı marka ürünlerin ithalatı artırdığı düşüncesindeki artış alman arabalara olan ilgiyi 0,6 kat azaltmıştır.

\section{Sonuç}

Son yıllarda ülkemizde yerli araba üretimi konusunda hükümet başta olmak üzere hızlı gelişmeler yaşanmaktadır. Otomotiv üretmek, üretilen arabaların pazarlanması, satış sonrası hizmetler bu konuda uzman ülkelerle rekabet yerli otomotiv sektörünün gelişimi açısından önemli kriterler olarak gözükmektedir. Türkiye de 2017 yılında 956 bin araç satılması sadece binek otomobilde 2016 yılında 10 milyar dolar civarında ithalat yapılması yerli araba üretimi konusunda tartışmaların gerekliliği ve özgüllüğü konusunda önemli ispatlardir.

Çalışmada Türkiye'de satılan 3 arabadan biri olan Alman marka otomobillere olan ilginin nedenleri araştırılmaya çalışılmıştır. Alman marka otomobillerin hem Türkiye'de hem de 
dünyada büyük ilgi görmesinin nedenleri yerli otomobil üretimi konusuna 1 şık tutabilecektir. Sonuçlar göstermektedir ki kişilerin tüketim yaparken imaj algısı, güvenlik algısı, tek bir kere alıp uzun zaman kullanma algısı arttıkça Alman arabalara ilgi artmaktadır. Ayrıca son 8 yılda Türkiye'de iki milyondan fazla Alman marka araç satılması da konunun başka akademik çalışmalara ilham kaynağı olabilecektir.

\section{Kaynakça}

Akay, E. \& Tümsel, B . (2016). Hanehalkı Otomobil Sahipliğinin İncelenmesi: Ardışık Logit Modeli. Sosyal Bilimler Araştırma Dergisi, 4 (4), 35-45.

Akçi, Y.(2016). İkinci El Otomobil: Tüketici Bakışıla. Adıyaman Üniversitesi Sosyal Bilimler Enstitüsü Dergisi, yı1 8, sayı 22, 329-362.

Çokluk Ömay.(2010) Kuram ve Uygulamada Eğitim Bilimleri / Educational Sciences: Thory \& Practice 10 (3) • Yaz / Summer 2010 • 1357-1407

Ersoy, H. \& Fırat, A.(2006). Türk otomotiv sanayinde markaların tüketici tercihleri üzerine etkisi. Dokuz eylül üniversitesi sosyal bilimler enstitüsü dergisi sayı 8, cilt 1, 200-211. Arıtan, T. \& Akyüz, A.M.(2015). Tüketicilerin Otomobil Markalarına Yönelik Marka Sadakatleri Ve Tercihleri Üzerine Bir Araştırma. Uluslararası Yönetim İktisat ve İşletme Dergisi, Sayı 26, Cilt 11, 195-220.

Güneş, S.(2012). Türk Toplumu ve Otomobil. SDÜ Fen Edebiyat Fakültesi Sosyal Bilimler Dergisi, Sayı:25, 213-230.

KALAYCI, Ş. (2005). "SPSS Uygulamalı Çok Değişkenli İstatistik Teknikleri”, Ankara, Asil Yayın Dağıtım, 1.Baskı, Ankara.

Karadirek, G.(2017). Satın Alma Niyetini Etkileyen Faktörler: Otomobil Markaları Üzerine Bir Uygulama. Ordu Üniversitesi Sosyal Bilimler Araştırmaları Dergisi, 7(2), 185 198. 
Köksal, Y.\& Türedi, M. (2014). Tüketici Otomobil Tercihinde Etkili Olan Bilgi Ve İletişim Kanalları Üzerine Bir İnceleme, Balıkesir Üniversitesi Sosyal Bilimler Enstitüsü Dergisi, Sayı 32, Cilt 17, 105-125.

ODD. (2017). Dünya Otomotiv Pazarı - 2017 3. Çeyrek. İstanbul.

ODD. (2018). Otomobil ve Hafif Ticari Araç Pazarı, Basın Bülteni. İstanbul.

ODD.(2017). Avrupa Otomobil Pazarı. Basın Bülteni. İstanbul.

ODD.(2018). Otomobil ve Hafif Ticari Araç Pazarı. Basın Özeti. İstanbul.

Pişkin, S.(2017). Otomotiv Sektör Raporu. TSKB Ekonomik Araştırmalar, Ankara.

Rijnsoever, F.V.\& Farla, J.\& Dijst, M.J. (2009). Consumer Car Preferences and Information Search Channels. Transportation Research, Part D 14, 334-342.

Ruhlusaraç M. \& Nakip, M.(2016). Akademisyenlerin Otomobil Satın Alım Tercihlerini Etkileyen Faktörler, Uluslararası Bilimler Araştırması Dergisi, sayı 1, Cilt 1, 99-111.

ŞENEL, S. \& ALATLI, B . (2014). Lojistik Regresyon Analizinin Kullanıldığı Makaleler Üzerine Bir İnceleme. Eğitimde ve Psikolojide Ölçme ve Değerlendirme Dergisi, 5 (1), 35 52. DOI: $10.21031 /$ epod.67169

Terzi, Ü.\& Hacaloğlu, S.E.\& Aladağ Z.(2006). Otomobil Satın Alma Problemi İçin Bir Karar Destek Modeli. İstanbul Ticaret Üniversitesi Fen Bilimleri Dergisi , Y1l: 5 Sayı:10, 43-49

Toksarı, M.\& İnal, E.M.(2011). Tüketici Temelli Marka Değerinin Ölçümü: Kayseri’de Otomobil Kullanıcıları Üzerine Bir Uygulama. Çağ Üniversitesi Sosyal Bilimler Dergisi, $8(2), 69-97$.

Tuik, Basın Odası Haberleri, Sayı 94, Ağustos 2016.

Ünsal E.M.(1998). Mikro İktisat. Kutsan ofset matbaacılık. Ankara. 
Yayar, Y.\& Çoban, N.M.\& Tekin, B. (2015). Otomobil Sahipliğini Etkileyen Faktörlerin Belirlenmesi: Tokat İli Kentsel Alanda Bir Uygulama. Yönetim ve Ekonomi 22/2, 603-617 